\title{
Ursolic acid suppresses the invasive potential of colorectal cancer cells by regulating the TGF-ß1/ZEB1/miR-200c signaling pathway
}

\author{
LING ZHANG ${ }^{1,2}$, QIAO-YAN CAI ${ }^{1,2}$, JIANXIN LIU $^{1}$, JUN PENG $^{1,2}$, \\ YOU-QIN CHEN ${ }^{1,3}$, THOMAS J. SFERRA ${ }^{1,3}$ and JIU-MAO LIN ${ }^{1,2}$
}

\author{
${ }^{1}$ Academy of Integrative Medicine; ${ }^{2}$ Fujian Key Laboratory of Integrative Medicine on Geriatrics, \\ Fujian University of Traditional Chinese Medicine, Fuzhou, Fujian 350122, P.R. China; ${ }^{3}$ Department of Pediatrics, \\ Case Western Reserve University School of Medicine, Rainbow Babies and Children's Hospital, Cleveland, OH 44106, USA
}

Received November 19, 2018; Accepted June 19, 2019

DOI: $10.3892 / \mathrm{ol} .2019 .10604$

\begin{abstract}
Ursolic acid (UA) is a biologically active compound, commonly used in traditional Chinese medicine (TCM). It has been reported to exhibit strong anticancer properties against a variety of cancers. Our previous studies showed that UA promoted apoptosis in colorectal cancer (CRC) cells and inhibited cellular proliferation and angiogenesis. However, the effect and underlying molecular mechanism of UA in CRC progression remain unclear. In the present study, the role of UA in suppressing the migration and invasion of human colon cancer HCT116 and HCT-8 cells was investigated, using Transwell assays. In addition, to evaluate whether the anticancer properties of UA were mediated by the regulation of a double-negative feedback loop consisting of the transforming growth factor- $\beta 1$ (TGF- $\beta 1$ )/zinc finger E-box-binding homeobox (ZEB1) pathway and microRNA (miR)-200a/b/c, reverse transcription-quantitative PCR and western blot analysis were performed. The results indicated that UA treatment significantly suppressed cellular growth, migration and invasion in HCT116 and HCT-8 cells in a dose-dependent manner. Furthermore, following UA treatment, several crucial mediators of the TGF- $\beta 1$ signaling pathway, including TGF- $\beta 1$, phosphorylated (p)-Smad2/3, p-focal adhesion kinase and ZEB1, were significantly downregulated in the HCT116 and HCT-8 cell lines compared with the control group. Furthermore, the ratio of $\mathrm{N}$-cadherin/E-cadherin, two proteins
\end{abstract}

Correspondence to: Professor Jiu-Mao Lin, Academy of Integrative Medicine, Fujian University of Traditional Chinese Medicine, 1 Qiu Yang Road, Fuzhou, Fujian 350122, P.R. China

E-mail: linjiumao@fjtcm.edu.cn

Abbreviations: CRC, colorectal cancer; UA, ursolic acid; TCM, Traditional Chinese Medicine; miR-200a/b/c, microRNA-200a/b/c; EMT, epithelial-mesenchymal transition; TGF- $\beta 1$, transforming growth factor- $\beta 1$; T $\beta$ R-I, type I TGF- $\beta 1$ receptor; ZEB, zinc finger E-box-binding homeobox; FAK, focal adhesion kinase

Key words: ursolic acid, colorectal cancer, invasion, microRNA-200c, transforming growth factor- $\beta$ signaling pathway directly downstream of the TGF- $\beta 1$ signaling pathway, was found to be downregulated in UA treated CRC cells. Finally, UA significantly upregulated miR200a/b/c, with miR-200c exhibiting the highest increase in expression levels following UA treatment. Collectively, the present study suggested that inhibition of CRC cell invasion by UA occurred via regulation of the TGF- $\beta 1 / \mathrm{ZEB} 1 / \mathrm{miR}-200 \mathrm{c}$ signaling network, which may be one of the mechanisms by which UA appears to be an effective therapeutic agent against colon cancer.

\section{Introduction}

Globally, colorectal cancer (CRC) is one of the most common types of cancer (1). At the early stage of CRC (i.e., stages I and II), CRC is amenable to surgery and curative treatment, with a 5-year survival rate $>60 \%$ for patients with CRC. However, $>50 \%$ of patients present with advanced disease (at or beyond stage III) and a high incidence of distant metastasis (2). In these patients, the 5-year survival rate drops to $10 \%$ (2). During metastatic progression, cancer cells can detach from the primary tumor site, passing through the circulation system to form metastatic tumors in distant organs (3). The epithelial-mesenchymal transition (EMT) is a process that contributes to the early stages of cancer metastasis, in which polarized epithelial cells lose their cell polarity and cell-cell adhesion to acquire a mesenchymal phenotype (4). The EMT process allows cancer cells to gain migratory and invasive properties that promote cancer metastasis (4). Since metastasis is considered as the leading cause of failure in cancer treatment, the development of novel pharmaceuticals for the prevention and treatment of cancer metastasis is critical.

The transforming growth factor (TGF)- $\beta 1$ pathway is essential to the EMT in cancer cells. In this process, TGF- $\beta 1$ initiates downstream signaling, by the dimerized TGF- $\beta 1$ ligand binding to the type III TGF- $\beta 1$ receptor, which then presents the ligand to the type II TGF- $\beta 1$ receptor, which leads to the phosphorylation of the type I TGF- $\beta 1$ receptor (T $\beta R-I)(5,6)$. In canonical TGF- $\beta 1$ signaling, activated T $\beta$ R-I phosphorylates the intracellular proteins $\operatorname{Smad} 2 / 3$, which in turn bind to Smad4, before translocating into the nucleus where they initiate transcriptional changes of target genes, including of the zinc finger E-box-binding homeobox (ZEB) 
family $(7,8)$. ZEB members act as suppressors of these transcriptional factors, downregulating epithelial markers, such as E-cadherin, while upregulating mesenchymal markers, such as $\mathrm{N}$-cadherin, which contributes to the development of cancer metastasis (9). In addition, TGF- $\beta 1$ can also signal through the non-canonical pathway, which includes focal adhesion kinase (FAK). TGF- $\beta 1$ has been shown to induce the Src-dependent phosphorylation of FAK, and its consequent activation is required for the upregulation of mesenchymal and invasiveness markers and the delocalization of E-cadherin, which promotes metastasis of cancer cells (10).

microRNAs (miRNAs) represent a class of non-coding RNAs, that are 21-24 nucleotides long, that suppress target gene expression in a sequence specific manner (11). The dysregulation of several miRNAs has been identified to induce EMT and promote colorectal metastasis associated with poorer survival (12). The miR-200 family consists of five members, including $\mathrm{miR}-200 \mathrm{a} / \mathrm{b} / \mathrm{c}$, miR-141 and miR-429, and has been shown to be master regulators of EMT, promoting cell dissemination from the primary tumor and subsequent metastasis (13). Indeed, loss of miR-200a/b/c expression has been shown to promote cellular metastasis in several cancers by inhibiting the ZEB transcription factor family and is correlated with poorer survival in patients with CRC (14-16). Notably, at the miRNA level, DNA methylation of $\mathrm{miR}-200 \mathrm{a} / \mathrm{b} / \mathrm{c}$ is a key mechanism in the negative regulation of its expression, which has been reported to be mediated by TGF- $\beta 1$ signaling (17). Thus, the TGF- $\beta 1 / \mathrm{ZEB} / \mathrm{miR}-200 \mathrm{a} / \mathrm{b} / \mathrm{c}$ signaling network (a positive correlation between TGF- $\beta 1$ and ZEB, negative correlations between TGF- $\beta 1$ and $\mathrm{miR}-200 \mathrm{a} / \mathrm{b} / \mathrm{c}$ and between miR-200a/b/c and ZEB) supports the maintenance of the mesenchymal phenotype required for metastasis (18).

Worldwide, agents used in Traditional Chinese Medicine (TCM) have received increasing interest in recent years for the treatment of various cancers, due to relatively low toxicity and few side effects (19). There is an urgent need to identify naturally occurring agents for effective anticancer treatments. Ursolic acid (UA) is present in many herbs and plants used in TCM, including Hedyotic diffusa, Scutellaria barbata, Spica prunellae and Patrinia scabiosaefolia, and possesses excellent anticancer properties against various types of cancers, including CRC (20-23). Increasing evidence indicates that UA has several biological properties, such as anti-inflammatory, antiviral, antioxidant, cytotoxic, anticancer, and antidiabetic (24-30). Our previous studies have shown that UA induced CRC cell apoptosis and suppressed cell proliferation and CRC angiogenesis via multiple signaling pathways $(28,29)$. In the present study, the effect of UA on CRC cell migration and invasion in vitro was further evaluated and the potential molecular mechanisms of its action were elucidated.

\section{Materials and methods}

Material and reagents. UA was purchased from Sigma-Aldrich (Merck KGaA). RPMI-1640 medium, PBS and penicillin-streptomycin were purchased from Hyclone (GE Healthcare Life Sciences). Fetal bovine serum (FBS) and trypsin-EDTA were obtained from Gibco (Thermo Fisher Scientific. Inc.). 3-(4,5-dimethylthiazol-2-yl)-2, 5-diphenyltetrazolium bromide (MTT) was purchased from Beijing Solarbio
Science \& Technology Co., Ltd. miR-200a/b/c and U6 primers were synthesized by Takara Biotechnology Co., Ltd. RNAiso for small RNA kit, Mir-X ${ }^{\mathrm{TM}}$ miRNA First-Strand Synthesis kit and TB Green ${ }^{\mathrm{TM}}$ Premix Ex Taq II kit were purchased from Takara Biotechnology Co., Ltd. N-cadherin (cat. no. ab18203) and E-cadherin (cat. no. ab1416) antibodies were purchased from Abcam. TGF- $\beta 1$ (cat. no. 3711), phosphorylated (p-) Smad2/3 (cat. no. 8828), Smad2/3 (cat. no. 8685), p-FAK (cat. no. 3284), FAK (cat. no. 71433), ZEB1 (cat. no. 3396) and horseradish peroxidase (HRP)-conjugated secondary antibodies (anti-rabbit IgG; cat. no. 7074; and anti-mouse IgG; cat. no. 7076) were purchased from Cell Signaling Technology, Inc. The $\beta$-actin antibody (cat. no. 66009-1-Ig) was purchased from ProteinTech Group, Inc. The Transwell chambers were obtained from Corning Life Sciences and the BD BioCoat Matrigel Invasion Chamber was purchased from BD Bioscience. All the other chemicals, unless otherwise stated, were obtained from Sigma-Aldrich (Merck KGaA).

Cell culture. Human colon cancer HCT116 and HCT-8 cell lines were obtained from the Nanjing KeyGen Biotech. Co. Ltd. Cells were cultured in RPMI-1640 medium, supplemented with $10 \% \mathrm{FBS}, 100 \mathrm{U} / \mathrm{ml}$ penicillin and $100 \mathrm{mg} / \mathrm{ml}$ streptomycin in a $37^{\circ} \mathrm{C}$ humidified incubator supplemented with $5 \% \mathrm{CO}_{2}$.

MTT assay. UA was dissolved in DMSO and diluted with culture medium to the desired concentrations. The final concentration of DMSO in the culture medium was $<0.1 \%$ throughout the study. HCT116 and HCT-8 cells were plated into 96-well plates at a $1 \times 10^{4}$ cells/well and treated with 0,10 , 20, $40 \mu \mathrm{M}$ UA for $24 \mathrm{~h}$ and $48 \mathrm{~h}$. Treatment with DMSO was included as the vehicle control. Following treatment, $100 \mu \mathrm{l}$ of $0.5 \mathrm{mg} / \mathrm{ml} \mathrm{MTT} \mathrm{solution} \mathrm{was} \mathrm{added} \mathrm{in} \mathrm{each} \mathrm{well} \mathrm{at} 37^{\circ} \mathrm{C}$ for $4 \mathrm{~h}$. The MTT formazan precipitate was dissolved in $100 \mu \mathrm{l}$ of DMSO. Subsequently, the resulting absorbance of the purple formazan product was determined at $570 \mathrm{~nm}$ with a ELX800 microplate reader (BioTek Instruments, Inc.). The cell viability was determined using the formula: Cell viability $(\%)=$ sample optical density (OD)/control OD x100.

Transwell assay. To evaluate the cell migration and invasion, Transwell assays were conducted using Transwell cell culture chambers with $8 \mu \mathrm{m}$ pore filters (Corning Life Sciences). After treatment with $0,10,20,40 \mu \mathrm{M}$ of UA for $24 \mathrm{~h}, \mathrm{HCT} 116$ and HCT- 8 cells were harvested and resuspended in serum-free RPMI-1640 without UA. Then, $\sim 5 \times 10^{4}$ cells that survived after the indicated concentrations of UA treatment for $24 \mathrm{~h}$ were seeded into the upper chambers. The lower chambers were filled with RPMI-1640 media containing 10\% FBS as a chemoattractant. Cells were allowed to migrate towards the complete medium for $12 \mathrm{~h}$ in the migration assay, the non-migrating cells in the upper chamber were wiped and the migrated cells were stained with crystal violet for $15 \mathrm{~min}$ at room temperature. For quantification, the average number of migrated cells per field was assessed by counting three random fields under a phase contrast microscope (Leica Microsystems $\mathrm{GmbH}$ ) at a magnification of $\mathrm{x} 200$. The cell invasion assay was similar to the migration assay, except that the upper chambers were coated with Matrigel matrix (BD Biosciences). 

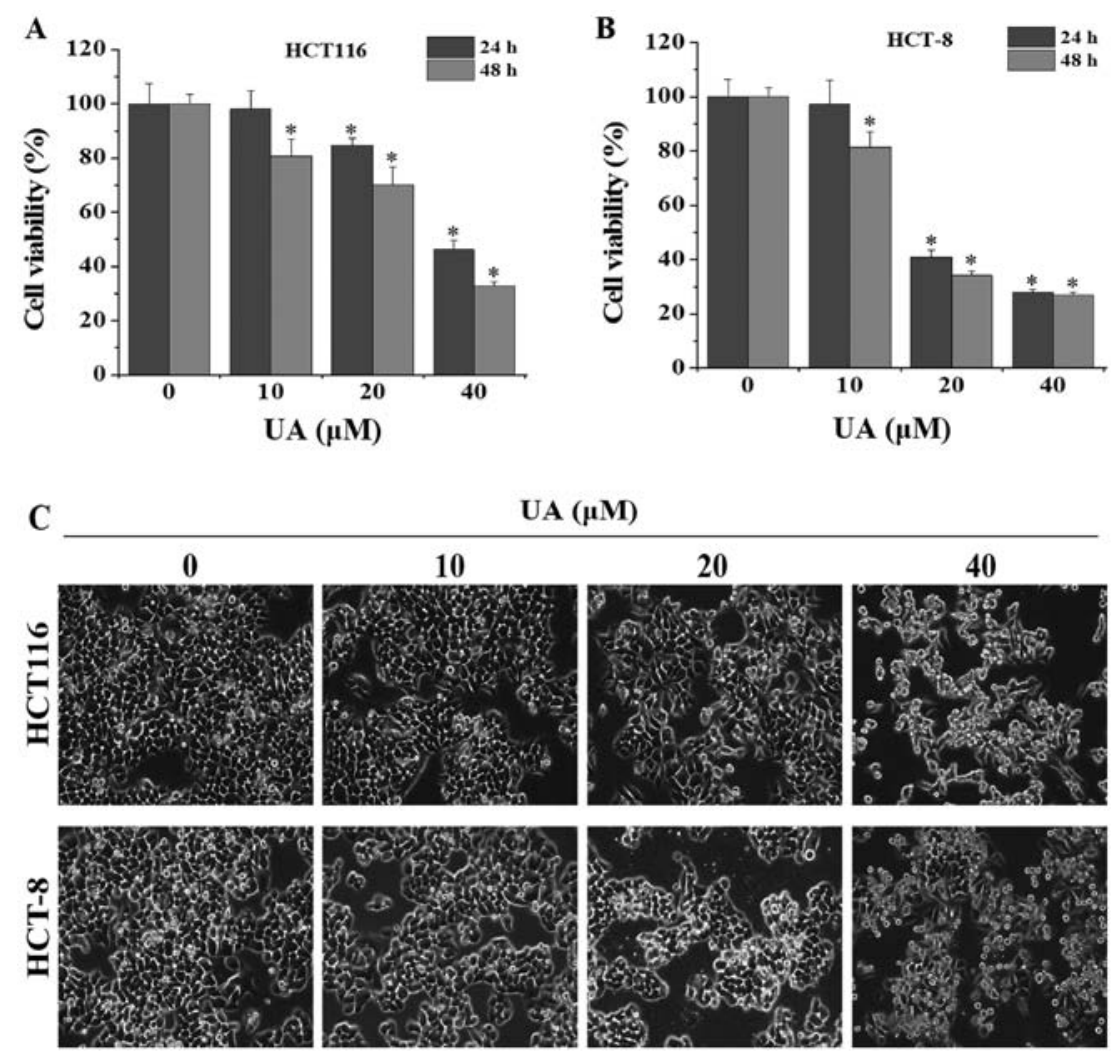

Figure 1. Effect of UA on the viability of HCT116 and HCT-8 cells. (A) HCT116 and (B) HCT-8 cell viability was determined following treatment with $0,10,20,40 \mu \mathrm{M}$ UA for $24 \mathrm{~h}$ or $48 \mathrm{~h}$, respectively. Data were normalized to the viability of untreated control cells. Data are expressed as the mean \pm standard deviation from three independent experiments. " $\mathrm{P}<0.01$ vs. untreated control cells. (C) HCT116 and HCT- 8 cell morphology was determined via phase-contrast microscopy following treatment with $0,10,20,40 \mu \mathrm{M}$ UA for $24 \mathrm{~h}$. UA, ursolic acid.

$R N A$ extraction and reverse transcription-quantitative polymerase chain reaction $(R T-q P C R)$ analysis. Following treatment with the indicated concentrations of UA for $24 \mathrm{~h}$, total small RNA was extracted using RNAiso for small RNA kit. Total small RNA was reverse transcribed with an Mir-X ${ }^{\mathrm{TM}}$ miRNA First-Strand Synthesis kit following the manufacturer's protocol. The primers for miR-200a (cat. no. DHM0178), miR-200b (cat. no. DHM0179), miR-200c (cat. no. DHM0180) and U6 (cat. no. D356-03) were obtained from Takara Biotechnology Co., Ltd. The obtained cDNA was used to determine the levels of miR-200a, miR-200b and miR-200c using TB Green ${ }^{\mathrm{TM}}$ Premix Ex Taq II in an ABI 7500 Fast PCR system, according to the manufacturer's instructions. The PCR conditions were as follows: Pre-denaturation at $95^{\circ} \mathrm{C}$ for $2 \mathrm{~min}$, then 45 cycles of $95^{\circ} \mathrm{C}$ for $3 \mathrm{sec}$ and $60^{\circ} \mathrm{C}$ for $30 \mathrm{sec}$. U6 was used as an internal control. Relative quantification was performed using the $2^{-\Delta \Delta C q}$ method (31). Each PCR amplification was carried out in triplicate.

Western blot analysis. After treatment with the indicated concentrations of UA for $24 \mathrm{~h}$, total protein was extracted with cell lysis buffer (Pierce; Thermo Fisher Scientific, Inc.) containing protease and phosphatase inhibitors. The concentration of total protein was detected using a bicinchoninic acid assay. A total of $50 \mu \mathrm{g}$ protein was separated on $10 \%$ SDS-PAGE gels and transferred onto nitrocellulose membranes (EMD Millipore Corporation). The membranes were blocked with $0.5 \%$ BSA for $2 \mathrm{~h}$ at room temperature and then probed with primary antibodies against TGF- $\beta 1$
(1:1,000), p-Smad2/3 (1:1,000), Smad2/3 (1:1,000), p-FAK $(1: 1,000)$, FAK $(1: 1,000), \mathrm{N}$-cadherin $(1: 1,000)$, E-cadherin $(1: 2,000)$, ZEB1 $(1: 1,000)$ and $\beta$-actin $(1: 5,000)$ overnight at $4^{\circ} \mathrm{C}$, followed by $1 \mathrm{~h}$ incubation with the anti-rabbit IgG HRP-conjugated secondary antibodies $(1: 2,000)$ or anti-mouse IgG HRP-conjugated secondary antibodies $(1: 2,000)$ at room temperature. Subsequently, using TBS/Tween-20 to wash the membranes, the immunoreactive bands were visualized via Image Lab software (version 3.0; Bio-Rad Laboratories, Inc.) using enhanced chemiluminescence (Yuheng Biotechnology Co., Ltd.).

Statistical analysis. All data were expressed as mean \pm standard deviation. Data were analyzed using SPSS software (version 16.0; SPSS Inc.). Statistical analysis was performed using one-way analysis of variance and least significant difference post hoc test. $\mathrm{P}<0.05$ was considered to indicate a statistically significant difference.

\section{Results}

UA inhibits the growth of HCT116 and HCT-8 cells. To evaluate the inhibitory effect of UA on the growth of HCT116 and HCT-8 cells, MTT assays were performed. UA treatment significantly inhibited cell viability in both a dose- and time-dependent manner (Fig. 1A and B). After $24 \mathrm{~h}$ of treatment, the half maximal inhibitory concentration $\left(\mathrm{IC}_{50}\right)$ values of UA for HCT116 and HCT- 8 cells were calculated to be 37.2 and $25.2 \mu \mathrm{M}$, respectively. Similarly, after $48 \mathrm{~h}$ of treatment, 


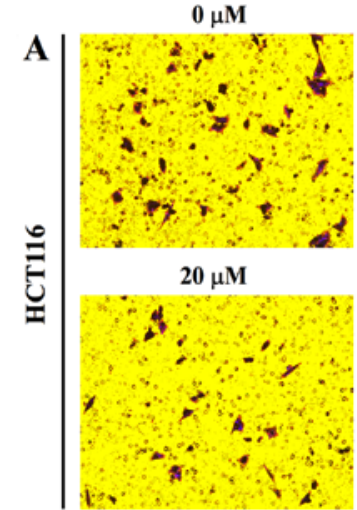

$\mathbf{0} \mu \mathbf{M}$

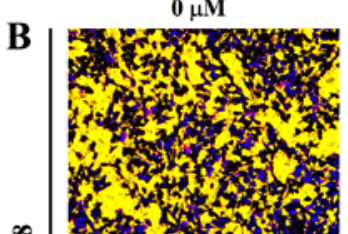

药

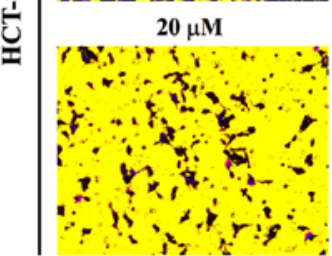

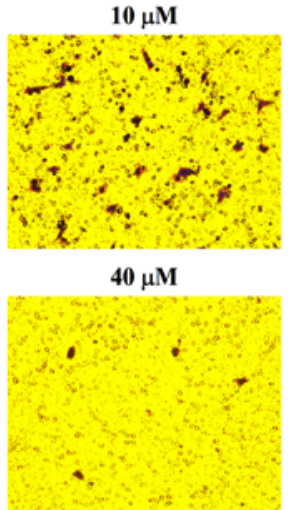

$10 \mu \mathrm{M}$

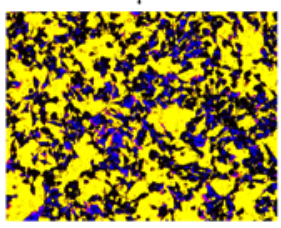

$40 \mu \mathrm{M}$
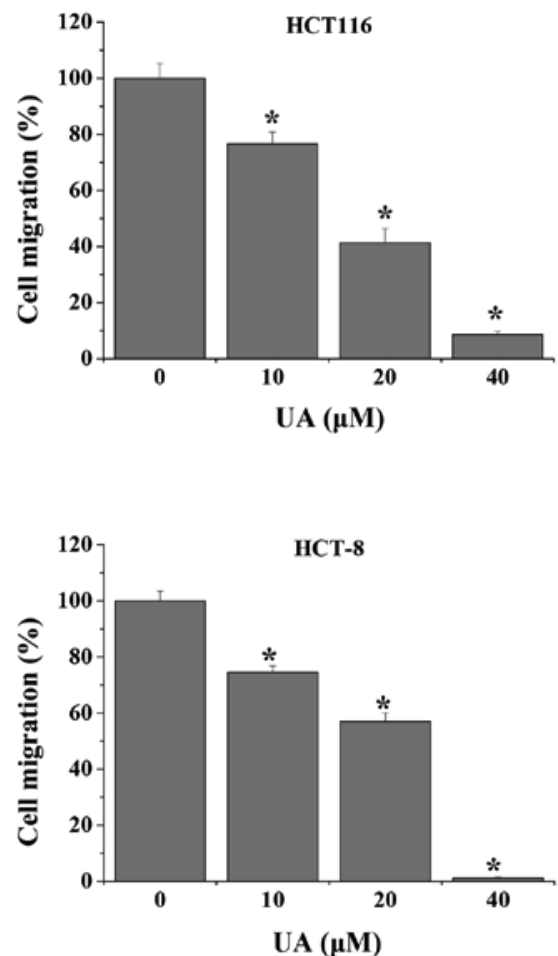

Figure 2. Effect of UA on the migration of HCT116 and HCT-8 cells. (A) HCT116 and (B) HCT-8 cell migration was determined using Transwell assays, following treatment with $0,10,20,40 \mu \mathrm{M}$ UA for $24 \mathrm{~h}$. Cells were stained with crystal violet; the images were captured at a magnification of $\mathrm{x} 200$. The average numbers of migrated cells were counted in three random fields on the lower surface of the membrane. Data were normalized to the untreated control cells. Data are expressed as the mean \pm standard deviation from three independent experiments. ${ }^{*} \mathrm{P}<0.01$ vs. untreated control cells. UA, ursolic acid.
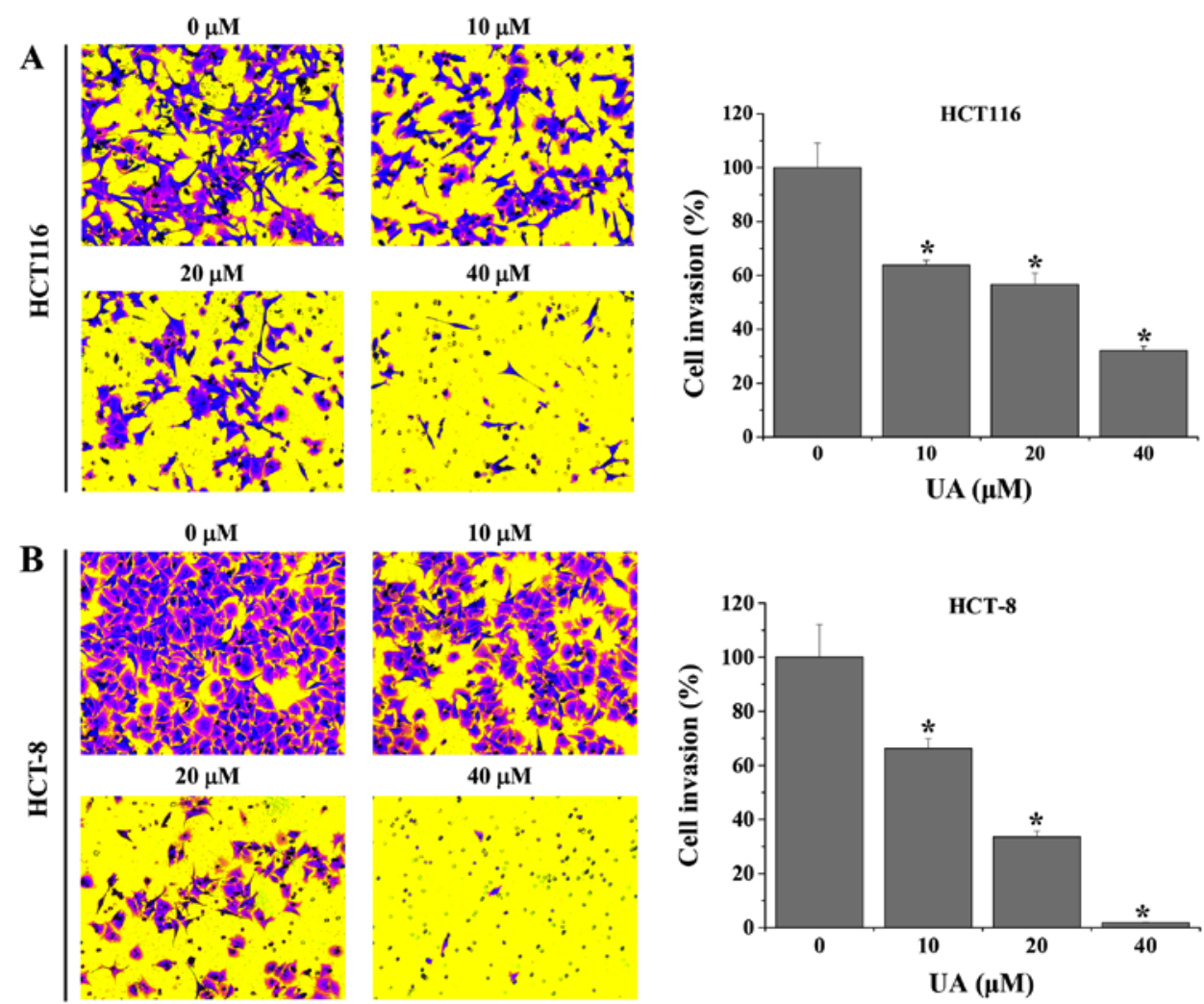

Figure 3. Effect of UA on the invasion of HCT116 and HCT-8 cells. (A) HCT116 and (B) HCT-8 cell invasion was determined using Matrigel-coated Transwell assays, following treatment with $0,10,20,40 \mu \mathrm{M}$ UA for $24 \mathrm{~h}$. Cells were stained with crystal violet; the images were captured at a magnification of x 200 . The average numbers of invasive cells were counted in three random fields on the lower surface of the membrane. Data were normalized to the untreated control cells. Data are expressed as the mean \pm standard deviation from three independent experiments. " $\mathrm{P}<0.01$ vs. untreated control cells. UA, ursolic acid. 
A

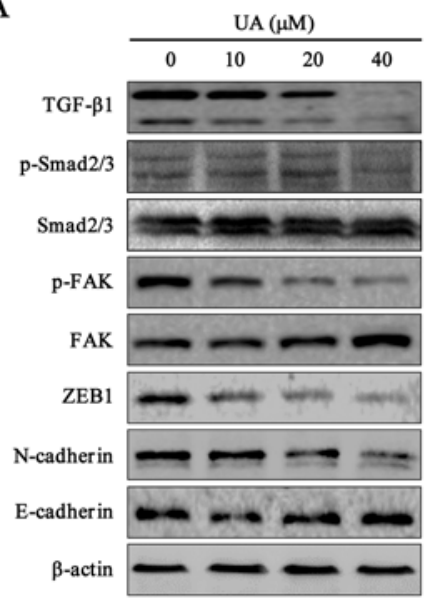

B

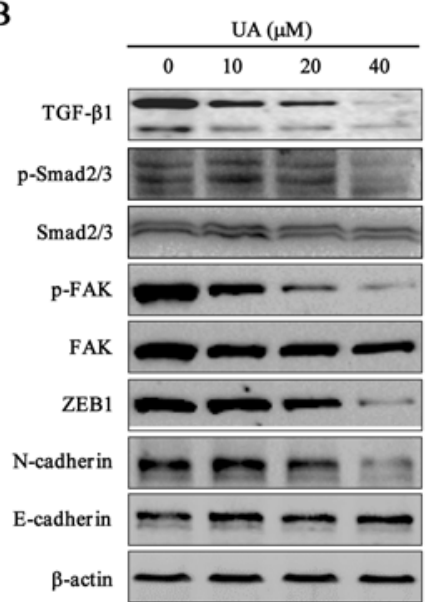

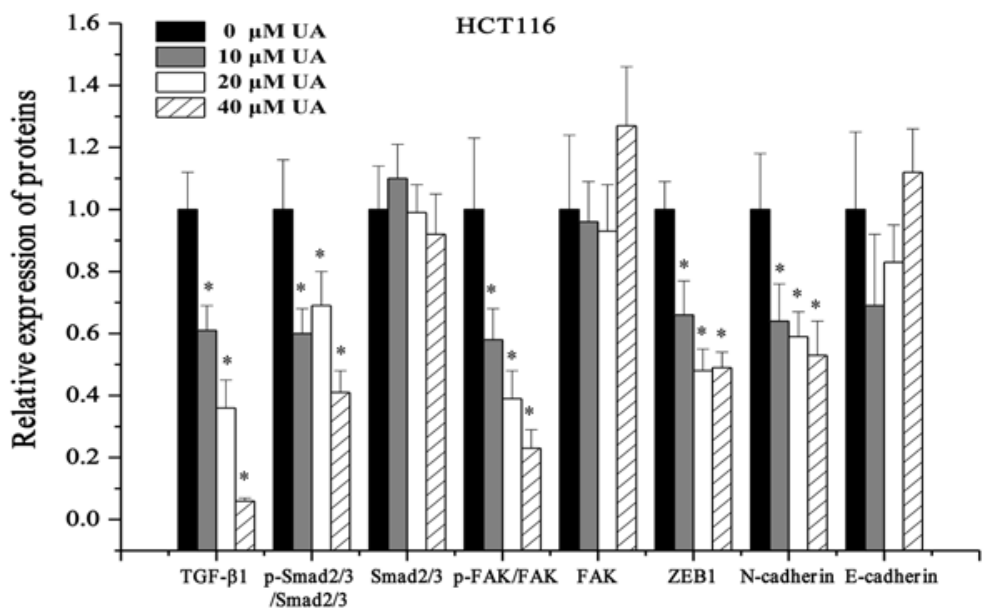

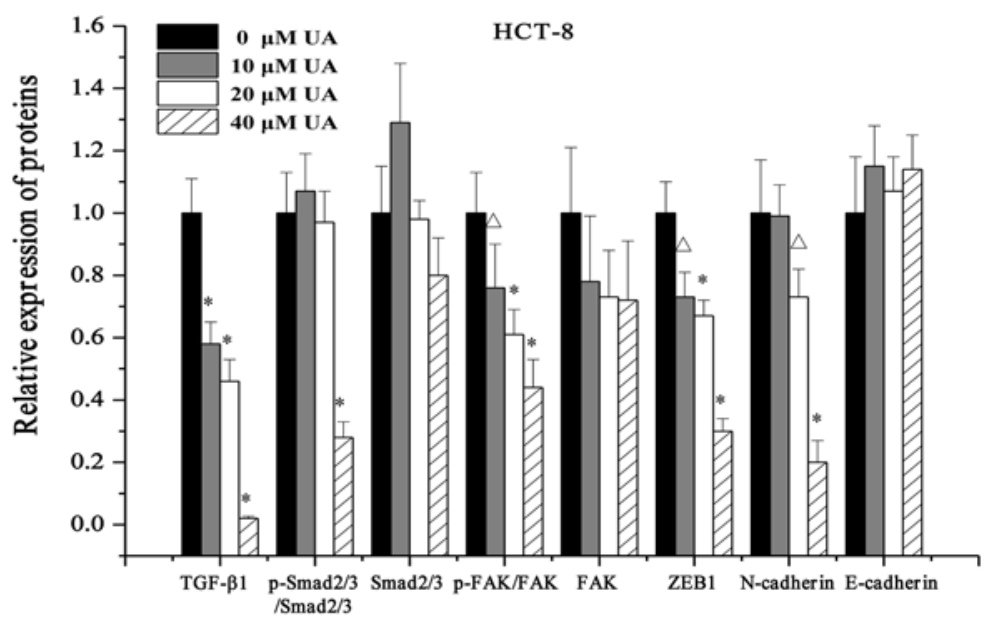

Figure 4. Effect of UA on the expression of TGF- $\beta 1$ pathway-associated proteins in HCT116 and HCT- 8 cells. (A) The protein expression levels of TGF- $\beta 1$, p-Smad2/3, Smad2/3, p-FAK, FAK, ZEB1, N-cadherin and E-cadherin in HCT116 and (B) HCT-8 cells were determined using western blot analysis following treatment with $0,10,20,40 \mu \mathrm{M}$ UA for $24 \mathrm{~h}$. $\beta$-actin was used as the internal control. Images are representative of three independent experiments. Relative densitometric analysis is shown. ${ }^{\triangle} \mathrm{P}<0.05$ and ${ }^{\mathrm{N}} \mathrm{P}<0.01$ vs. untreated control cells. UA, ursolic acid; TGF- $\beta 1$, transforming growth factor $\beta 1 ; \mathrm{p}$-, phosphorylated; FAK, focal adhesion kinase; ZEB, zinc finger E-box-binding homeobox.

the $\mathrm{IC}_{50}$ values of UA were determined to be 28.0 and $19.4 \mu \mathrm{M}$ for HCT116 and HCT-8 cells, respectively. Cells exhibiting condensed and fragmented nuclei are considered as growth inhibited. Phase-contrast microscopy was used to examine the effect of UA on HCT116 and HCT-8 cell morphology. Untreated control cells were observed in a confluent monolayer, healthy and attached to the culture plate, whereas UA treatment significantly decreased the confluence of these two cell lines and resulted in condensed, fragmented and detached cells, in a dose-dependent manner (Fig. 1C). Taken together, these results indicated that UA significantly inhibited the growth of HCT116 and HCT- 8 cells.

UA inhibits migration and invasion in HCT116 and HCT-8 cells. Transwell assays were performed to evaluate the effect of UA on the migration of HCT116 and HCT-8 cells. As shown in Fig. 2, the results demonstrated that treatment with 10-40 $\mu \mathrm{M}$ UA significantly decreased the migratory rate of HCT116 and HCT- 8 cells by $23.3 \pm 4.2-91.3 \pm 1.2 \%$ and $25.5 \pm 2.4-98.8 \pm 0.2 \%$, respectively, when compared with untreated cells. Furthermore, UA was demonstrated to inhibit the invasive abilities of HCT116 and HCT- 8 cells. The results revealed that the invasion rate of HCT116 and HCT-8 cells following UA treatment was $36.2 \pm 1.8-67.9 \pm 1.6 \%$ and $33.8 \pm 3.7-98.2 \pm 0.2 \%$, respectively, compared with that in the untreated cells (Fig. 3). Taken together, these results suggest that UA exhibited an inhibitory effect on the migration and invasion properties of HCT116 and HCT- 8 cells in a dose-dependent manner.

UA inhibits TGF- $\beta 1 /$ Smad and TGF- $\beta 1 / F A K$ signaling pathways and regulates EMT-related proteins in HCT116 and HCT-8 cells. EMT has been shown to be associated with the metastasis of tumor cells (32). TGF- $\beta 1$ signaling pathways, including the canonical TGF- $\beta 1 /$ Smad pathway and the non-canonical TGF- $\beta 1 /$ FAK signaling pathway, can trigger EMT $(10,33)$. To better understand whether UA inhibited TGF- $\beta 1$ signaling pathways, the expression of several pivotal mediators of TGF- $\beta 1 /$ Smad and TGF- $\beta 1 / F A K$ signaling pathways was assessed in HCT116 and HCT-8 cells. As shown in Fig. 4, western blot analysis revealed that UA treatment $(0,10$, 20 , and $40 \mu \mathrm{M})$ dose-dependently decreased the expression 
A

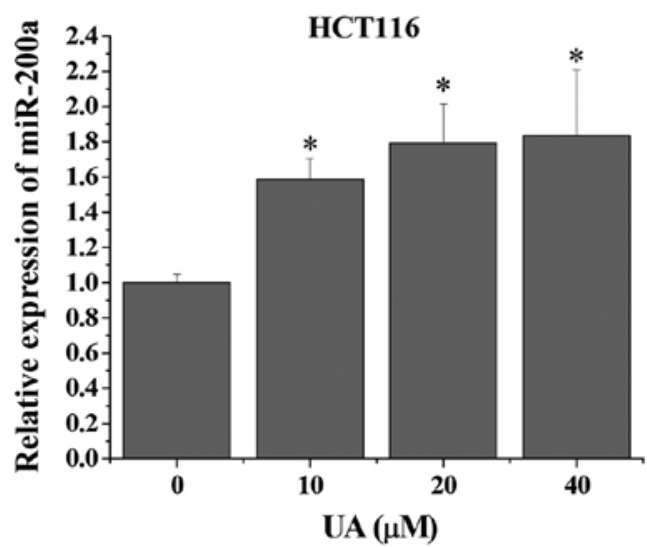

B

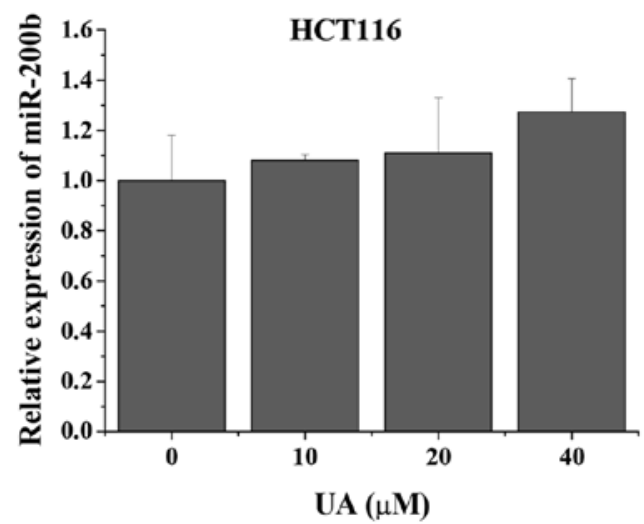

C

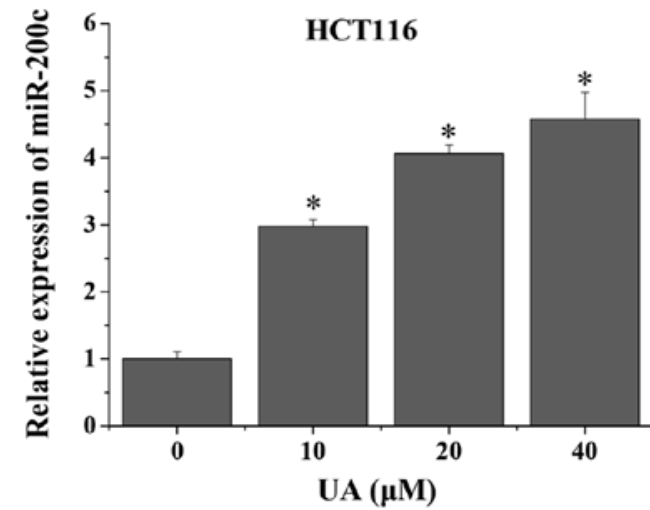

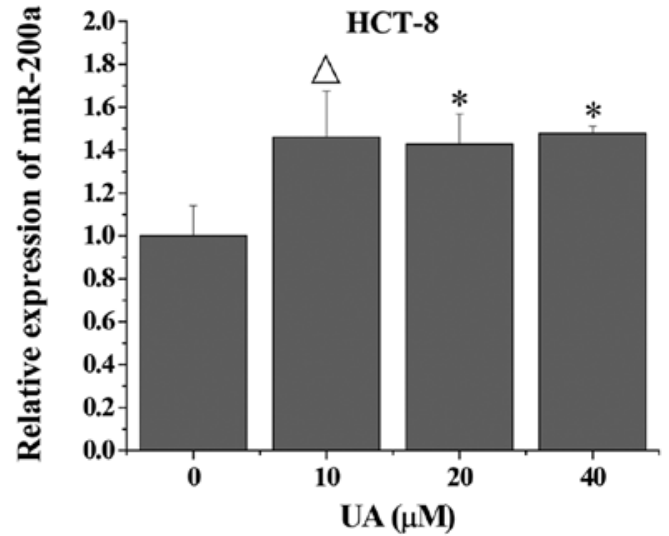
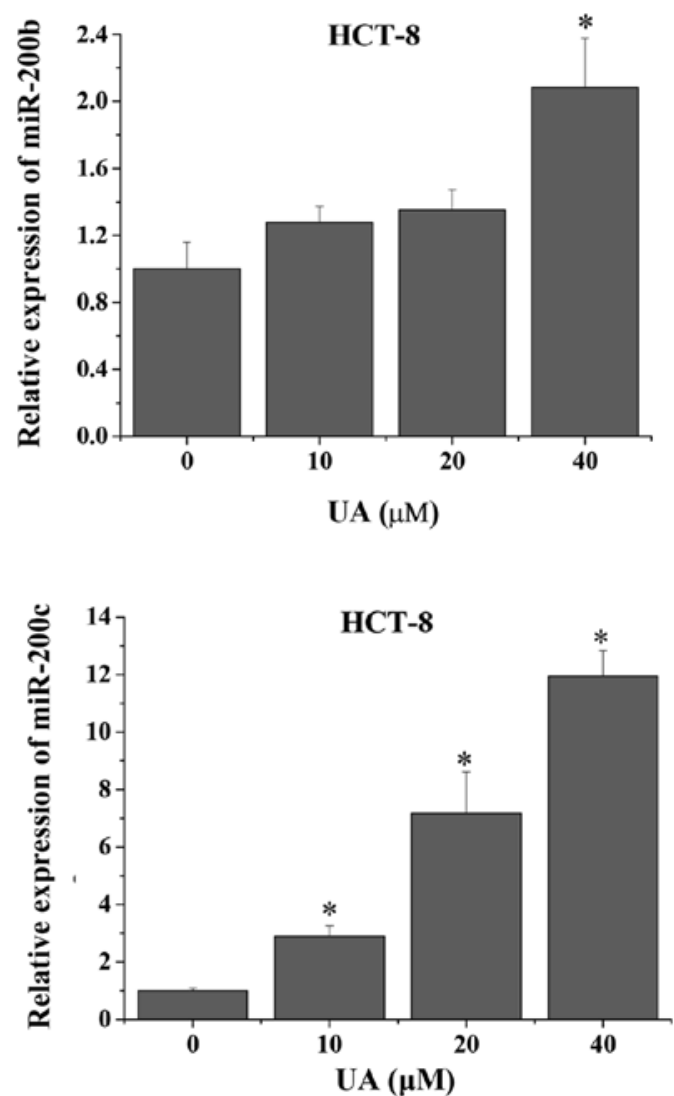

Figure 5. Effect of UA on the expression of miR-200a/b/c in HCT116 and HCT-8 cells. The expression levels of (A) miR-200a, (B) miR-200b and (C) miR-200c in HCT116 and HCT- 8 cells were determined using reverse transcription-quantitative PCR analysis following treatment with $0,10,20,40 \mu \mathrm{M}$ UA for $24 \mathrm{~h}$. U6 was used as the internal control. ${ }^{\Delta} \mathrm{P}<0.05$ and ${ }^{*} \mathrm{P}<0.01$ vs. untreated control cells. UA, ursolic acid; miR, microRNA.

levels of TGF- $\beta 1$, and the expression levels of the TGF- $\beta 1$ target gene ZEB1. Activation of Smad2/3 and FAK is mediated by their phosphorylation, and UA treatment also significantly reduced the phosphorylation levels of both $\operatorname{Smad} 2 / 3$ and FAK (Fig. 4). Inhibition of the TGF- $\beta 1 / \mathrm{Smad}$ and TGF- $\beta 1 /$ FAK signaling pathways by UA led to a decrease in the expression of the mesenchymal marker $\mathrm{N}$-cadherin compared with that in the control cells (Fig. 4). However, no difference was observed between the control cells and UA-treated cells regarding the protein expression levels of the epithelial marker E-cadherin (Fig. 4). These results indicated that the antitumor properties of UA may be mediated by the inhibition of the TGF- $\beta 1$ signaling pathways.
$U A$ regulates the expression of $\mathrm{miR}-200 \mathrm{a} / \mathrm{b} / \mathrm{c}$ in $\mathrm{HCT116}$ and HCT-8 cells. miR-200a/b/c maintains the epithelial phenotype and inhibits cell metastasis via downregulation of its target gene ZEB1 (34). In this process, TGF- $\beta 1$ signaling increases the DNA methylation of miR-200a/b/c, thereby negatively regulating its expression (17). Thus, to further investigate whether UA inhibited colorectal cell invasion via regulation of the TGF- $\beta 1 / \mathrm{ZEB} 1 / \mathrm{miR}-200 \mathrm{a} / \mathrm{b} / \mathrm{c}$ feedback loop, the expression levels of miR-200a/b/c were determined via RT-qPCR analysis. As shown in Fig. 5, the expression levels of miR-200a and miR-200c in HCT116 and HCT-8 cells were significantly increased following UA treatment compared with that in the untreated control cells. While the expression 
levels of miR-200b did not significantly change after UA treatment in HCT116 cells compared with the untreated control, HCT- 8 cells exhibited a significant increase in miR-200b levels following treatment with $40 \mu \mathrm{M}$ UA (Fig. 5). These findings are consistent with the observation that UA inhibited the TGF- $\beta 1$ pathway and the expression of ZEB1 (Fig. 4). As shown in Fig. 5, the expression levels of miR-200c exhibited the highest increase following UA treatment. Therefore, the present results suggested that UA may inhibit cell growth and invasion in HCT116 and HCT-8 cells via regulation of the TGF- $\beta 1 /$ ZEB1/miR-200c feedback loop.

\section{Discussion}

UA is a natural triterpene acid present in various plants, fruits, flowers and berries used in TCM (35). It mediates several pharmacological processes and can be used as a preventive and therapeutic medicine against multiple chronic diseases, including cancer, metabolic syndrome, cardiovascular diseases, brain disease, liver disease, and sarcopenia (36). In particular, several studies have revealed the antitumor effects of UA in gastric (37), prostate (38), breast (39), lung (40), liver (41), and osteosarcoma cancer (42). It was observed that UA inhibited CRC cell growth while having no adverse effects on the weight of mice in vivo (29). In addition, UA significantly promotes CRC cell apoptosis and suppresses cell proliferation via the regulation of numerous $\mathrm{CRC}$-related signaling pathways, including STAT3, ERK, JNK, and p38 (29). Of note, UA also inhibits CRC angiogenesis through the suppression of several pivotal mediators, such as vascular endothelial growth factor-A and basic fibroblast growth factor. The inhibition of multiple signaling pathways, including those related to hedgehog, STAT3, AKT and ribosomal protein S6 kinase $\beta-1$, may be the potential mechanisms by which UA may represent a promising compound against tumor angiogenesis (28). Furthermore, UA has anti-inflammatory effects on a dextran sodium sulfate-mediated colitis model, whereas it has no effect on normal intestinal epithelial cells (data not shown). In the present study, the effect of UA on the metastatic potential of CRC cells was investigated. The inhibitory effect of UA on cell viability was confirmed in the human colon cancer cell lines HCT116 and HCT- 8 and these results are consistent with previous results in HT-29 cells (29). In addition, UA treatment significantly and dose-dependently inhibited the migration and invasion of HCT116 and HCT- 8 cells in Transwell assays, suggesting that UA may strong suppressive effects on cancer progression.

Metastasis is considered the predominant cause of malignant cancer progression (43). Similar to angiogenesis, the process of metastasis is complex and involves complicated interactions between the tumor and the stroma (44). Indeed, multiple signaling pathways are involved in metastasis, including the integrin pathway, the TGF- $\beta$ pathway, the chemokine pathway, and the dependence receptor pathway (45). These signaling pathways regulate multiple mesenchymal and invasiveness markers, as well as epithelial markers. A recent study has reported that UA inhibited the invasive phenotype of human gastric cancer cells by decreasing the expression of matrix metalloproteinase-2 (37). The synergism between UA and metformin has been shown to significantly inhibit the invasion and migration of breast cancer cells via modulation of the 5'-AMP activated protein kinase/TOR signaling pathways (46). Furthermore, UA attenuates EMT in non-small cell lung carcinoma by targeting integrin $\alpha \mathrm{V} \beta 5 /$ matrix metalloproteinase signaling (47). Aspirin combined with UA exhibits anti-metastatic ability via influencing both EMT and epidermal growth factor receptor-mediated pathways (48). In the present study, the focus was on the TGF- $\beta 1$ pathways, including canonical TGF- $\beta 1 /$ Smad and non-canonical TGF- $\beta 1 / F A K$. The results demonstrated that UA treatment significantly reduced the expression of several crucial mediators of these TGF- $\beta 1$ signaling pathways, including TGF- $\beta 1$, $\mathrm{p}-\mathrm{Smad} 2 / 3$, p-FAK and ZEB1, leading to a decrease in $\mathrm{N}$-cadherin protein expression. A recent study has shown that ZEB1 is the direct downstream target of $\mathrm{miR}-200 \mathrm{a} / \mathrm{b} / \mathrm{c}$ and is downregulated following miR-200a/b/c activation (49). miR-200a/b/c, ZEB1 and TGF- $\beta 1$ are known to regulate tumor progression (50-53), and increased the expression of $\mathrm{miR}-200 \mathrm{a} / \mathrm{b} / \mathrm{c}$ or the decrease in ZEB1 or TGF- $\beta 1$ could inhibit cancer cell EMT, which deactivates cellular mobility and subsequently suppresses tumor metastasis (54-57). Notably, the present study demonstrated that UA regulated the expression levels of $\mathrm{miR}-200 \mathrm{a} / \mathrm{b} / \mathrm{c}$, with miR-200c exhibiting the highest upregulation in HCT116 and HCT-8 cells following UA treatment.

In summary, UA inhibited the viability, migration and invasion of CRC cells in vitro, by modulating the TGF- $\beta 1 / Z E B 1 / m i R-200 c$ signaling network. The present findings elucidated the potential underlying mechanisms of UA, and suggested that it may be an effective and promising therapeutic agent in the treatment of CRC.

\section{Acknowledgements}

Not applicable.

\section{Funding}

The present study was sponsored by the National Natural Science Foundation of China (grant nos. 81704069 and 81774121), the Training of Young and Middle-aged Backbone Personnel of Fujian Provincial Health and Family Planning Commission (grant no. 2016-ZQN-67) and the Scientific Research Foundation of Traditional Chinese Medicine of Fujian Provincial Health and Family Planning Commission, China (grant no. 2017FJZYZY203).

\section{Availability of data and materials}

The datasets used and/or analyzed during the current study are available from the corresponding author on reasonable request.

\section{Authors' contribution}

LZ and JML conceived and designed the experiments, analyzed the data and drafted the manuscript. LZ, QYC and JXL performed the cell experiments. QYC, JXL and YQC performed the RT-qPCR and western blot experiments. TS and JP were involved in analyzing the data and revised the manuscript critically for important intellectual content. JML gave final approval of the version to be published. All authors read and approved the final manuscript. 


\section{Ethics approval and consent to participate}

Not applicable.

\section{Patient consent for publication}

Not applicable.

\section{Competing interest}

The authors declare that they have no competing interests.

\section{References}

1. Jemal A, Bray F, Center MM, Ferlay J, Ward E and Forman D Global cancer statistics, 2012. CA Cancer J Clin 61: 69-90, 2011

2. Mcquade RM, Stojanovska V, Bornstein JC and Nurgali K: Colorectal cancer chemotherapy: The evolution of treatment and new approaches. Curr Med Chem 24: 1537-1557, 2017.

3. Gupta GP and Massagué J: Cancer metastasis: Building a framework. Cell 127: 679-695, 2006.

4. Yang J and Weinberg RA: Epithelial-mesenchymal transition: At the crossroads of development and tumor metastasis. Dev Cell 14: 818-829, 2008.

5. López-Casillas F, Wrana JL and Massagué J: Betaglycan presents ligand to the TGF beta signaling receptor. Cell 73: 1435-1444, 1993

6. Franzén P, ten Dijke P, Ichijo H, Yamashita H, Schulz P, Heldin $\mathrm{CH}$ and Miyazono K: Cloning of a TGF beta type I receptor that forms a heteromeric complex with the TGF beta type II receptor. Cell 75: 681-692, 1993.

7. Chen Y,Lebrun JJ and Vale W: Regulation of transforming growth factor beta- and activin-induced transcription by mammalian Mad proteins. Proc Natl Acad Sci USA 93: 12992-12997, 1996.

8. Zhang Y, Feng X, Wu R and Derynck R: Receptor-associated mad homologues synergize as effectors of the TGF-beta response. Nature 383: 168-172, 1996.

9. Peinado H, Olmeda D and Cano A: Snail, Zeb and bHLH factors in tumour progression: An alliance against the epithelial phenotype? Nat Rev Cancer 7: 415-428, 2007.

10. Cicchini C, Laudadio I, Citarella F, Corazzari M, Steindler C, Conigliaro A, Fantoni A, Amicone L and Tripodi M TGFbeta-induced EMT requires focal adhesion kinase (FAK) signaling. Exp Cell Res 314: 143-152, 2008.

11. Chitwood DH and Timmermans MC: Small RNAs are on the move. Nature 467: 415-419, 2010.

12. Guo Y, Bao Y and Yang W: Regulatory miRNAs in colorectal carcinogenesis and metastasis. Int J Mol Sci 18: E890, 2017.

13. Knezevic J, Pfefferle AD, Petrovic I, Greene SB, Perou CM and Rosen JM: Expression of miR-200c in claudin-low breast cancer alters stem cell functionality, enhances chemosensitivity and reduces metastatic potential. Oncogene 34: 5997-6006, 2015.

14. Zhou X, Wang Y, Shan B, Han J, Zhu H, Lv Y, Fan X, Sang M, Liu XD and Liu W: The downregulation of miR-200c/141 promotes ZEB1/2 expression and gastric cancer progression. Med Oncol 32: 428, 2015

15. Wu WR, Sun H, Zhang R, Yu XH, Shi XD, Zhu MS, Zeng H, Yan LX, Xu LB and Liu C: Methylation-associated silencing of miR-200b facilitates human hepatocellular carcinoma progression by directly targetingBMI1. Oncotarget 7: 18684-18693, 2016

16. Kumar S, Nag A and Mandal CC: A comprehensive review on miR-200c, a promising cancer biomarker with therapeutic potential. Curr Drug Targets 16: 1381-1403, 2015.

17. Gregory PA, Bracken CP, Smith E, Bert AG, Wright JA, Roslan S, Morris M, Wyatt L, Farshid G, Lim YY, et al: An autocrine TGF-beta/ZEB/miR-200 signaling network regulates establishment and maintenance of epithelial-mesenchymal transition. Mol Biol Cell 22: 1686-1698, 2011.

18. Xiong M, Jiang L, Zhou Y, Qiu W, Fang L, Tan R, Wen P and Yang J: The miR-200 family regulates TGF- $\beta 1$-induced renal tubular epithelial to mesenchymal transition through Smad pathway by targeting ZEB1 and ZEB2 expression. Am J Physiol Renal Physiol 302: F369-F379, 2012.

19. Hsiao WL and Liu L: The role of traditional Chinese herbal medicines in cancer therapy-from tcm theory to mechanistic insights. Planta Med 76: 1118-1131, 2010.
20. Lin J, Wei L, Xu W, Hong Z, Liu X and Peng J: Effect of Hedyotis Diffusa Willd extract on tumor angiogenesis. Mol Med Rep 4: 1283-1288, 2011

21. Lin W, Zheng L, Zhuang Q, Zhao J, Cao Z, Zeng J, Lin S, Xu W and Peng J: Spica prunellaepromotes cancer cell apoptosis, inhibits cell proliferation and tumor angiogenesis in a mouse model of colorectal cancer via suppression of stat 3 pathway. BMC Complement Altern Med 13: 144, 2013.

22. Peng J, Chen Y, Lin J, Zhuang Q, Xu W, Hong Z and Sferra TJ: Patrinia scabiosaefolia extract suppresses proliferation and promotes apoptosis by inhibiting the STAT3 pathway in human multiple myeloma cells. Mol Med Rep 4: 313-318, 2011.

23. Zhang L, Fang Y, Feng JY, Cai QY, Wei LH, Lin S and Peng J: Chloroform fraction of Scutellaria barbata D. Don inhibits the growth of colorectal cancer cells by activating miR-34a. Oncol Rep 37: 3695-3701, 2017.

24. Checker R, Sandur SK, Sharma D, Patwardhan RS, Jayakumar S, Kohli V, Sethi G, Aggarwal BB and Sainis KB: Potent anti-inflammatory activity of ursolic acid, a triterpenoid antioxidant, is mediated through suppression of NF- $\mathrm{KB}, \mathrm{AP}-1$ and NF-AT. PLoS One 7: e31318, 2012.

25. Kong L, Li S, Liao Q, Zhang Y, Sun R, Zhu X, Zhang Q, Wang J, Wu X, Fang X and Zhu Y: Oleanolic acid and ursolic acid: Novel hepatitis $C$ virus antivirals that inhibit NS5B activity. Antiviral Res 98: 44-53, 2013.

26. Liobikas J, Majiene D, Trumbeckaite S, Kursvietiene L, Masteikova R, Kopustinskiene DM, Savickas A and Bernatoniene J: Uncoupling and antioxidant effects of ursolic acid in isolated rat heart mitochondria. J Nat Prod 74: 1640-1644, 2011.

27. Ma CM, Cai SQ, Cui JR, Wang RQ, Tu PF, Hattori M and Daneshtalab M: The cytotoxic activity of ursolic acid derivatives. Eur J Med Chem 40: 582-589, 2005.

28. Lin J, Chen Y, Wei L, Hong Z, Sferra TJ and Peng J: Ursolic acid inhibits colorectal cancer angiogenesis through suppression of multiple signaling pathways. Int J Oncol 43: 1666-1674, 2013.

29. Lin J, Chen Y, Wei L, Shen A, Sferra TJ, Hong Z and Peng J: Ursolic acid promotes colorectal cancer cell apoptosis and inhibits cell proliferation via modulation of multiple signaling pathways. Int J Oncol 43: 1235-1243, 2013.

30. Zhao YN, Zhang XX and Jiang H: A review on anti-diabetic effects of ursolic acid. Clin J Chin Med 8: 142-145, 2016 (In Chinese).

31. Livak KJ and Schmittgen TD: Analysis of relative gene expression data using real-time quantitative PCR and the 2(-Delta Delta C(T)) method. Methods 25: 402-408, 2001.

32. Heerboth S, Housman G, Leary M, Longacre M, Byler S, Lapinska K, Willbanks A and Sarkar S: EMT and tumor metastasis. Clin Transl Med 4: 6, 2015.

33. Pang L, Li Q, Wei C, Zou H, Li S, Cao W, He J, Zhou Y, Ju X, Lan J, et al: TGF- $\beta 1 /$ Smad signaling pathway regulates epithelial-to-mesenchymal transition in esophageal squamous cell carcinoma: In vitro and clinical analyses of cell lines and nomadic Kazakh patients from northwest Xinjiang, China. Plos One 9: e112300, 2014

34. Gregory PA, Bert AG, Paterson EL, Barry SC, Tsykin A, Farshid G, Vadas MA, Khew-Goodall Y and Goodall GJ: The miR-200 family and miR-205 regulate epithelial to mesenchymal transition by targeting ZEB1 and SIP1. Nat Cell Biol 10: 593-601, 2008.

35. Jäger S, Trojan H, Kopp T, Laszczyk MN and Scheffler A: Pentacyclic triterpene distribution in various plants-rich sources for a new group of multi-potent plant extracts. Molecules 14: 2016-2031, 2009.

36. Seo DY, Lee SR, Heo JW, No MH, Rhee BD, Ko KS, Kwak HB and Han J: Ursolic acid in health and disease. Korean J Physiol Pharmacol 22: 235-248, 2018.

37. Kim ES and Moon A: Ursolic acid inhibits the invasive phenotype of SNU-484 human gastric cancer cells. Oncol Lett 9: 897-902, 2015.

38. Meng Y, Lin ZM, Ge N, Zhang DL, Huang $\mathbf{J}$ and Kong F: Ursolic acid induces apoptosis of prostate cancer cells via the PI3K/Akt/mTOR pathway. Am J Chin Med 43: 1471-1486, 2015.

39. Wen JH, Wei XH, Sheng XY, Zhou DQ, Peng HW, Lu YN and Zhou J: Effect of ursolic acid on breast cancer resistance protein-mediated transport of rosuvastatin in vivo and vitro. Chin Med Sci J 30: 218-225, 2015.

40. Huang CY, Lin CY, Tsai CW and Yin MC: Inhibition of cell proliferation, invasion and migration by ursolic acid in human lung cancer cell lines. Toxicol In Vitro 25: 1274-1280, 2011.

41. Yan SL, Huang CY, Wu ST and Yin MC: Oleanolic acid and ursolic acid induce apoptosis in four human liver cancer cell lines. Toxicol In Vitro 24: 842-848, 2010. 
42. Wu CC, Cheng CH, Lee YH, Chang IL, Chen HY, Hsieh CP and Chueh PJ: Ursolic acid triggers apoptosis in human osteosarcoma cells via caspase activation and the ERK1/2 MAPK pathway. J Agric Food Chem 64: 4220-4226, 2016.

43. Yokota J: Tumor progression and metastasis. Carcinogenesis 21 : 497-503, 2000.

44. Langley RR and Fidler IJ: The seed and soil hypothesis revisited-the role of tumor-stroma interactions in metastasis to different organs. Int J Cancer 128: 2527-2535, 2011.

45. Robert J: Biology of cancer metastasis. Bull Cancer 100: 333-342, 2013 (In French).

46. Zheng G, Shen Z, Xu A, Jiang K, Wu P, Yang X, Chen X and Shao J: Synergistic chemopreventive and therapeutic effects of co-drug ua-met: Implication in tumor metastasis. J Agric Food Chem 65: 10973-10983, 2017.

47. Ruan JS, Zhou H, Yang L, Wang L, Jiang ZS, Sun H and Wang SM: Ursolic acid attenuates TGF- $\beta 1$ induced epithelial-mesenchymal transition in NSCLC by targeting integrin $\alpha \mathrm{V} \beta 5 / \mathrm{MMPs}$ signaling. Oncol Res 7: 593-600, 2017.

48. Tang Q, Liu Y, Li T, Yang X, Zheng G, Chen H, Jia L and Shao J: A novel co-drug of aspirin and ursolic acid interrupts adhesion, invasion and migration of cancer cells to vascular endothelium via regulating EMT and EGFR-mediated signaling pathways: Multiple targets for cancer metastasis prevention and treatment. Oncotarget 7: 73114-73129, 2016.

49. Burk U, Schubert J, Wellner U, Schmalhofer O, Vincan E, Spaderna $S$ and Brabletz T: A reciprocal repression between ZEB1 and members of the miR-200 family promotes EMT and invasion in cancer cells. EMBO Rep 9: 582-589, 2008

50. Li Y, Zeng C, Tu M, Jiang W, Dai Z, Hu Y, Deng Z and Xiao W: MicroRNA-200b acts as a tumor suppressor in osteosarcoma via targeting ZEB1. Onco Targets Ther 9: 3101-3111, 2016.

51. Tang H, Deng M, Tang Y, Xie X, Guo J, Kong Y, Ye F, Su Q and Xie X: miR-200b and miR-200c as prognostic factors and mediators of gastric cancer cell progression. Clin Cancer Res 19: 5602-5612, 2013.
52. Zhang HF, Xu LY and Li EM: A family of pleiotropically acting microRNAs in cancer progression, miR-200: Potential cancer therapeutic targets. Curr Pharm Des 20: 1896-1903, 2014.

53. Hasegawa Y, Takanashi S, Kanehira Y, Tsushima T, Imai T and Okumura K: Transforming growth factor-betal level correlates with angiogenesis, tumor progression, and prognosis in patients with nonsmall cell lung carcinoma. Cancer 91: 964-971, 2001.

54. Bracken CP, Gregory PA, Kolesnikoff N, Bert AG, Wang J, Shannon MF and Goodall GJ: A double-negative feedback loop between ZEB1-SIP1 and the microRNA-200 family regulates epithelial-mesenchymal transition. Cancer Res 68: 7846-7854, 2008.

55. Chen D, Wang J, Zhang Y, Chen J, Yang C, Cao W, Zhang H, Liu Y and Dou J: Effect of down-regulated transcriptional repressor ZEB1 on the epithelial-mesenchymal transition of ovarian cancer cells. Int J Gynecol Cancer 23: 1357-1366, 2013.

56. Chen D, Zhang Y, Wang J, Chen J, Yang C, Cai K, Wang X, Shi F and Dou J: MicroRNA-200c overexpression inhibits tumorigenicity and metastasis of CD117+ CD44+ ovarian cancer stem cells by regulating epithelial-mesenchymal transition. J Ovarian Res 6: 50, 2013.

57. Alb M, Sie C, Adam C, Chen S, Becker JC and Schrama D: Cellular and cytokine-dependent immunosuppressive mechanisms of grm1-transgenic murine melanoma. Cancer Immunol Immunother 61: 2239-2249, 2012.

This work is licensed under a Creative Commons Attribution-NonCommercial-NoDerivatives 4.0 International (CC BY-NC-ND 4.0) License. 